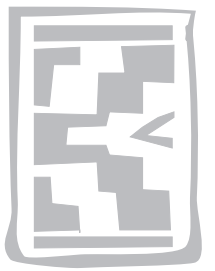

\title{
The effect of dexamethasone and promethazine in combination with buparvaquone in the management of East Coast fever
}

\author{
M. GWAMAKA ${ }^{1}$, J.A. MATOVELO ${ }^{1 *}$, M.M.A. MTAMBO ${ }^{2}$, G.K. MBASSA ${ }^{3}$, R.M. MASELLE ${ }^{1}$ \\ and S. BONIPHACE 1
}

\begin{abstract}
GWAMAKA, M., MATOVELO, J.A., MTAMBO, M.M.A., MBASSA, G.K., MASELLE, R.M. \& BONIPHACE, S. 2004. The effect of dexamethasone and promethazine in combination with buparvaquone in the management of East Coast fever. Onderstepoort Journal of Veterinary Research, 71: $119-128$

The effects of dexamethasone and promethazine on the amelioration of pulmonary oedema in East Coast fever were investigated. The clinical effects of these drugs were further investigated when used in conjunction with the antitheilerial drug, buparvaquone. In the first experiment, 15 crossbred (Friesian $x$ Zebu) steers were divided into four groups. With the exception of the animals in group IV, that served as a control group all the others were infected with Theileria parva sporozoites. On the second day of the febrile reaction, the steers in groups I and II were treated with dexamethasone $(0.1 \mathrm{mg} / \mathrm{kg})$ and promethazine $(1 \mathrm{mg} / \mathrm{kg})$, respectively. Group III steers served as the infected untreated controls. On the fifth day of the febrile reaction the animals in groups I, II and III were infused intravenously with tattoo ink suspension and $1 \mathrm{~h}$ later sacrificed for post-mortem examination and tissue sampling. The clinical picture indicated that both drugs significantly mitigated dyspnoea and the post mortem examination revealed a significant reduction in morphological changes. Tattoo ink particle count reflected a significant $(P<0.01)$ reduction in vascular leakage in the treated animals, with promethazine being significantly $(P<0.05)$ more effective than dexamethasone in this respect. In the second experiment, 18 steers were infected with $T$. parva sporozoites, and then were randomly allotted into three groups each of which contained six animals. After the onset of ECF clinical signs, the animals in the first two groups were treated with buparvaquone in combination with either dexamethasone (group I) or promethazine (group II), and the third group was treated with buparvaquone alone. The results indicated that all the animals in groups I, II and III recovered well and no significant differences were observed in clinical disposition between the groups. Two months later, serum samples were collected from the refractory animals and demonstrated the presence of antibodies against $T$. parva. When the animals were subsequently artificially challenged with $T$. parva, none of them succumbed to clinical disease. The same $T$. parva stabilate stock was used in both experiments and it proved to be infective in a separate batch of steers.
\end{abstract}

Keywords: Buparvaquone, dexamethasone, East Coast fever, promethazine, pulmonary oedema, Theileria parva

* Author to whom correspondence is to be directed

1 Department of Veterinary Pathology, Sokoine University of Agriculture, P.O. Box 3018 Chuo Kikuu, Morogoro, Tanzania

2 Department of Veterinary Medicine, Sokoine University of Agriculture, P.O. Box 3018 Chuo Kikuu, Morogoro, Tanzania

3 Department of Veterinary Anatomy, Sokoine University of Agriculture, P.O. Box 3018 Chuo Kikuu, Morogoro, Tanzania

Accepted for publication 10 November 2003-Editor

\section{INTRODUCTION}

East Coast fever (ECF), a disease of cattle caused by the protozoan parasite Theileria parva, is one of the most important diseases in central, eastern and southern African regions (Norval, Perry \& Young 1992). East Coast fever causes considerable loss to farmers through mortality of the affected animals 
and high cost of drugs against the disease (Mukhebi, Perry \& Kruska 1992). Pulmonary oedema is considered to be a potentially serious complication of ECF and is thought to be largely responsible for the deaths that occur (Jubb, Kennedy \& Palmer 1992). The mechanism of the development of oedema in ECF is by increased vascular permeability resulting from a combined action of anaphylatoxins $\mathrm{C} 3 \mathrm{a}$ and $\mathrm{C} 5 \mathrm{a}$, and vasoactive amines released by target cells during the disease process (Shitakha, Musoke, Ramasamy \& Buscher 1983; Lawrence, De Vos \& Irvin 1994). Despite aggressive antitheilerial therapy the recovery rate is usually poor in animals in the stage of the disease in which respiratory distress is manifested, the latter being attributed to pulmonary oedema (Mbwambo, Mkonyi \& Chuwa 1987; Norval et al. 1992). In such situations combined therapy with other supportive drugs, such as diuretics, glucocorticoids, and antihistamines is considered to improve the prospects of such cases (Mbwambo, Mkonyi \& Chuwa 1984; Thaiyah, Chege, Muriuki \& Wekesa 1993; Mbwambo, Sudi, Mkonyi, Mfinanga, Mella \& Ngovi 2002). This combination of chemotherapeutic agents administered to animals suffering from ECF has been in use for some time and has given encouraging results (Mbwambo et al. 1984; Thaiyah et al. 1993; Matovelo, Mwamengele \& Mbassa 2000). Diuretics, such as furosemide should, at least theoretically, reduce pulmonary oedema and this is the reason why formulations of antitheilerial drugs with furosemide are commercially available. However, furosemide only reduces the body fluids (Adams 2001) and may not have any effect in the prevention of the development of inflammatory oedema. The suppressive effect of glucocorticoids on the development of pulmonary oedema in ECF has been demonstrated by Matovelo et al. (2000). Also, the use of antihistamines such as tripelennamine hydrochloride (Vetibenzamine ${ }^{\circledR}$ ) has shown to improve the recovery rate of ECF cases (Thaiyah et al. 1993). Despite the wide use of glucocorticoids and antihistamines in the management of clinical cases in the field, an in-depth study on their supportive role has not yet been conducted.

The pharmacological effects of glucocorticoids, such as dexamethasone, include the reduction of movement of proteins and other vascular fluids to the damaged tissues by maintaining vascular integrity and antagonizing the effect of toxins and kinins (Adams 2001). In the current study, the choice of dexamethasone as supportive drug was based on the assumption that it would antagonize the effects of chemical mediators of inflammation that induce increased vascular permeability in ECF. Antihist- amines bind specifically to the $\mathrm{H} 1$-receptors in tissue cells thereby limiting the accessibility of histamine to these receptors (Adams 2001). Since the effects of anaphylatoxins C3a and C5a on vascular permeability are mainly through the degranulation of mast cells followed by histamine release (Slauson \& Cooper 2001), it was hypothesized that the use of antihistamines in the treatment of ECF would prevent the formation of pulmonary oedema. The aim of this study was, therefore, to study and compare the effectiveness of dexamethasone and promethazine in preventing the development of pulmonary oedema in ECF as well as to determine their supportive role in the therapy of clinical cases of ECF when used in conjunction with an antitheilerial drug. In this study, the effect of dexamethasone and promethazine on vascular permeability changes was assessed by using carbon particles in tattoo ink; this method has been used before (Young \& Spradbrow 1990; Matovelo et al. 2000) and was found to be effective both qualitatively and quantitatively.

\section{MATERIALS AND METHODS}

\section{Experimental animals}

Thirty-five susceptible Friesian (Bos taurus) $x$ Zebu (Bos indicus) steers, from 8-11 months old, were obtained from farms in Morogoro, Tanzania. Strict tick control is practised on these farms. All the animals were screened for $T$. parva by examining Giemsa-stained lymph node and blood smears. The animals were also screened for antibodies to $T$. parva schizont antigens using an indirect fluorescent antibody test (IFAT) (Burridge \& Kimber 1972). The animals were fed on hay, maize bran and molasses, and had ad libitum access to water throughout the study period.

\section{Inoculation of the animals}

Theileria parva Muguga stabilate 3087 , obtained from the International Livestock Research Institute (ILRI) Nairobi, Kenya, was used for infection. The sporozoites were kept in plastic straws of $0.5 \mathrm{~m} \ell$ capacity $\left(10^{5-8}\right.$ sporozoites per straw) that were transported in containers containing solid carbon dioxide $\left(\mathrm{CO}_{2}\right)$, and were subsequently stored in liquid nitrogen. Prior to inoculation of the cattle, the straws and their contents were thawed by immersion in lukewarm water (about $37^{\circ} \mathrm{C}$ ) for $3 \mathrm{~min}$. The animals were inoculated subcutaneously in the neck region immediately cranial to the left prescap- 
ular lymph node. Each animal received $0.5 \mathrm{~m} \ell$ of the stabilate.

\section{Clinical monitoring, lymph node smears and blood sampling}

The rectal temperatures of the inoculated cattle as well as those of the uninfected control animals were monitored daily. On day 6 after infection smears were made from material obtained by needle biopsy of the left prescapular lymph node. These were fixed in methyl alcohol, stained with Giemsa and examined by light microscopy for the presence of schizonts. In cases where schizonts could not be demonstrated, the needle lymph node biopsies were performed and smears made and examined on a daily basis until schizonts were detected. In addition, the size of the superficial lymph nodes, lung sounds monitored by auscultation and respiration rate were closely monitored. Blood for serological assay was collected in $3 \mathrm{~m} \ell$ amounts in plain tubes by direct puncture of the external jugular vein with a hypodermic needle.

\section{Experiment 1-vascular permeability study}

Fifteen steers were used in this study. They were randomly allocated into four treatment groups. Group I consisted of four steers that were used to investigate the effect of dexamethasone on the development of pulmonary oedema, group II of four steers that were used to study the effect of promethazine on the development of pulmonary oedema, group III of four steers that served as infected, untreated controls and group IV of three animals that served as uninfected, untreated controls.

\section{Glucocorticoid therapy}

Glucocorticoid therapy was instituted on the second day of the febrile reaction [10 days post infection (p.i.)]. The drug administered to the steers in group I was dexamethasone (Coopavet, Ancenis, France), formulated as dexamethasone sodium phosphate at $2 \mathrm{mg} / \mathrm{m} \ell$ equivalent to $1.52 \mathrm{mg} / \mathrm{m} \ell$ dexamethasone base. The drug was given at a dose of 0.1 $\mathrm{mg} / \mathrm{kg}$ of body mass by intramuscular injection for three consecutive days.

\section{Antihistamine therapy}

Antihistamine therapy was instituted on the second day of febrile reaction (10 days p.i.). The drug administered to the steers in group III was promethazine hydrochloride (Sterop, Brussels, Belgium) formulated at $50 \mathrm{mg} / \mathrm{m} \ell$ and given at the dosage rate of $1 \mathrm{mg} / \mathrm{kg}$ of body mass by intramuscular injection for three consecutive days.

\section{Vascular permeability assessment}

Assessment of vascular permeability was attempted by using black tattoo ink suspension (Stone Manufacturing and Supply Company, Kansas City, Missouri 94127, USA). Desiccated tattoo ink was reconstituted by suspending $75 \mathrm{mg}$ in $1 \mathrm{~m} \ell$ normal saline (Matovelo et al. 2000). This suspension was filtered through Whatman $®$ filter paper $(91), 11 \mathrm{~cm}$ diameter (Whatman International Ltd, Maidstone England). On day 13 p.i. (fifth day of the febrile reaction in the infected cattle), the freshly prepared suspension was administered into the external jugular vein at a rate of $1 \mathrm{~m} \ell / \mathrm{kg}$ body mass over a period of 15 min using an infusion set.

\section{Post mortem examination and tissue sampling}

One hour after the tattoo ink infusion, the animals in all groups were deeply anaesthetised using pentobarbitone sodium (VMD-Chemie N.V., Arendonk, Belgium). This drug was formulated as a $60 \mathrm{mg} / \mathrm{m} \ell$ solution and administered intravenously at the dosage rate of $15 \mathrm{mg} / \mathrm{kg}$ body mass. The animals were then exsanguinated and subjected to full post mortem examination. Lung appearance, size and amount of fluid/froth in the airways, as well as the amount of transudate in the abdominal and pleural cavities was assessed and given scores to represent the degree of severity. Severely enlarged and oedematous lungs were given a score of 2 whereas lungs that showed slight enlargement and mild morphological changes were scored as 1 . Normal appearing lungs were given a score of 0 . Copious fluid/froth in the trachea was scored as 2 , a moderate or mild amount of froth or fluid in the trachea was scored as 1 , and where there was no froth or fluid in the trachea it was scored as 0 . The lungs and heart were weighed separately using a mechanical beam balance. Changes in lung mass were expressed in the lung mass to heart mass ratio. Other gross post mortem lesions were also recorded. Tissues for histopathological studies were taken from four lung lobes in each steer. These were preserved in 10\% neutral buffered formalin.

\section{Tissue processing for histopathological studies}

Tissue sections for histopathological studies were prepared for light microscopy using standard procedures and were stained with haematoxylin and eosin (Bancroft \& Stevens 1990). Selected tissue 
changes were photographed using Agfapan ASA 25 film.

\section{Enumeration of tattoo ink carbon particles by microscopical means}

In each of the tissue sections of the four lung lobes, five primary lobules were randomly selected. In each selected lobule, 20 alveoli were purposely selected for carbon particle enumeration. The criterion for alveoli selection was based on whether the interalveolar tissue space associated with the alveoli revealed a reasonably even distribution of particles. All the particles in the alveoli were counted. The average counts were computed in each lobule and its respective lobe.

\section{Experiment II—combination chemotherapy study}

In this experiment, 18 cattle were experimentally infected with $T$. parva and randomly allotted into three groups, each consisting of six steers. The first group received the combined treatment of buparvaquone (Pitman-Moore Ltd, Harefield, United Kingdom) and promethazine, the second group received buparvaquone and dexamethasone and third group buparvaquone alone. Animals were considered infected when schizonts were present in the smears made from materials obtained by needle biopsy of the left prescapular lymph node of each animal and rectal temperature above $39.4^{\circ} \mathrm{C}$. The animals were treated with the selected chemotherapeutics once the clinical signs of coughing, reduced appetite and dullness had been observed. Buparvaquone was given according to the manufacturer's instructions whereas dexamethasone $(0.1 \mathrm{mg} / \mathrm{kg}$ intramuscularly) and promethazine (1 $\mathrm{mg} / \mathrm{kg}$ intramuscularly) were given once a day for three consecutive days. Prior to treatment lymph node smears made from the right and left prescapular lymph nodes were fixed, stained and examined, and the numbers of lymphocytes containing schizonts were scored using the method of McHardy, Wekesa, Hudson \& Randall (1985) with some modifications. The same procedures were repeated on day 5 , after completion of the treatment. The sizes of all superficial lymph nodes, lung sounds, respiration patterns and other clinical changes were monitored and recorded daily.

\section{Experiment III-re-infection study}

After 60 days those animals in Experiment II that had recovered from the treatment, were again inoculated with the same T. parva stabilate at the same dosage rate. In addition, the two steers that had not been allocated into either Experiment I or II were similarly infected to ascertain the viability of the $T$. parva inoculum. Inoculation procedures and clinical and parasitological monitoring were carried out as mentioned for the experiments above. In addition, on days 7 and 14 after the schizonts were first detected, lymph node smears were made again and examined for $T$. parva schizonts.

\section{Statistical analysis}

Data on particle counts and lung mass changes were analysed using a student $t$-test. Clinical and necropsy attributes were compared by Chi-square analyses and differences were considered significant at $P<0.05$.

\section{RESULTS}

At the commencement of the study all experimental animals were free of parasites in both lymph node and blood smears, and serum samples were negative to antibodies to T. parva schizont antigens.

\section{Experiment I}

\section{Clinical observations}

All T. parva-infected animals developed clinical ECF within 2 weeks of infection. The mean time to detection of schizonts was $7.6 \pm 0.22$ day p.i. and the temperatures rose to $39.5^{\circ} \mathrm{C}$ in $8.55 \pm 0.22$ day p.i. Lymph node enlargements was detected as early as $7.5 \pm 0.18$ day p.i.

At the time when the treatment commenced, all infected animals were clinically ill. The proportions of infected animals with dyspnoea in each group are shown in Fig. 1. In group I only one of the steers $(25 \%)$ became dyspnoeic by day 11 p.i, while the other three $(75 \%)$ had apparently normal respiratory performance. Treatment with promethazine also mitigated dyspnoea in $75 \%$ of the animals in the group; only $25 \%$ developed dyspnoea by day 12 p.i. In the infected untreated control group, $75 \%$ of the animals developed dyspnoea on day $12 \mathrm{p.i}$, and one animal become dyspnoeic on day 13 p.i. The clinical response to the treatment in groups I and II therefore indicated that the two drugs significantly $(P<0.05)$ mitigated dyspnoea as compared to the untreated control group. Diarrhoea and coughing were observed in a small non-significant proportion of animals in all treatment groups. 
TABLE 1 Necropsy scores of the four groups of cattle in experiment 1

\begin{tabular}{|l|l|l|l|l|}
\hline \multirow{2}{*}{ Variable } & \multicolumn{4}{l}{ Group } \\
\cline { 2 - 5 } & I & II & III & IV \\
\hline Changes in lung appearance & $1 / 8^{*}$ & $3 / 8^{*}$ & $5 / 8$ & $0 / 6$ \\
Fluid/froth in the airways & $3 / 8$ & $3 / 8$ & $7 / 8$ & $0 / 6$ \\
Fluid in body cavities & $3 / 8$ & $2 / 8$ & $2 . / 8$ & $0 / 6$ \\
\hline
\end{tabular}

Data are expressed as positive score/Total score expected for which variable was recorded

* Significantly different $(P<0.05)$ from the infected, untreated control

TABLE 2 Mean ( \pm s.e) lung and heart mass $(\mathrm{kg})$ changes in T. parva infected cattle

\begin{tabular}{|l|l|l|l|l|}
\hline \multirow{2}{*}{ Variable } & \multicolumn{4}{l|}{ Group } \\
\cline { 2 - 5 } & I & II & III & IV \\
\hline Lungs & $1.17 \pm 0.08$ & $1.41 \pm 0.27$ & $1.49 \pm 0.15$ & $1.07 \pm 0.23$ \\
Heart & $0.57 \pm 0.04$ & $0.67 \pm 0.11$ & $0.52 \pm 0.02$ & $0.64 \pm 0.17$ \\
Lungs/heart ratio & $2.07 \pm 0.15$ & $2.21 \pm 0.39$ & $2.56 \pm 0.28^{*}$ & $1.65 \pm 0.05$ \\
\hline
\end{tabular}

* Significantly different $(P<0.05)$ from the uninfected control
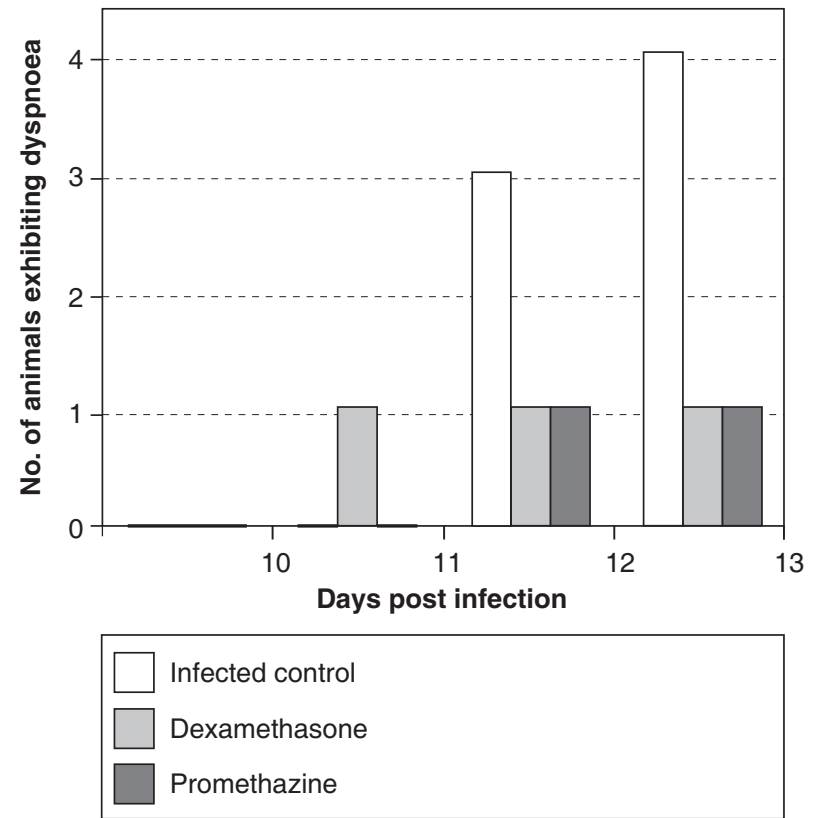

FIG.1 Respiratory performance in the T. parva infected cattle treated with supportive drugs (dexamethasone in group I or promethazine in group II) and the untreated control animals

\section{Gross pathological features}

The necropsy scores are summarized in Table 1. Based on the appearance of the lungs, group I steers were significantly $(P<0.05)$ less affected than in groups II and III. Although fluid/froth in the trachea was a common finding in the animals in groups I, II and III, the scores assigned to represent the severity showed that group I and group II were significantly $(P<0.05)$ less affected than those in the infected untreated control group. Mild ascites and hydrothorax were seen in all animals in groups I, II and III but the differences between these groups were not statistically significant $(P>0.05)$. The transudate in the body cavities was pale brown, clear and serous in nature, with the exception of one animal where the fluid had a brownish yellow discoloration, and was turbid and fibrinous in nature.

Lung mass changes as expressed in lung:heart mass ratios are shown in Table 2. A significant increase $(P<0.05)$ in the mean lung mass from the baseline value of uninfected control group was only recorded in the infected untreated control animal group, whereas in the treated animal groups the increases were not significant.

\section{Histopathology and vascular permeability changes}

Lung sections from all $T$. parva infected animals revealed haemorrhages, necrosis of parenchyma cells and moderate infiltration of lymphocytes in the interstitial tissue. In addition, the Infected untreated control animals revealed a widening of interlobular septa as a result of oedema. Few macrophages laden with carbon particles were seen in the interstitium and in the alveoli. 
Dexamethasone and promethazine in combination with buparvaquone in East Coast fever

TABLE 3 Average tattoo ink particle count in the alveoli in each cattle in experiment I

\begin{tabular}{|l|l|l|l|l|l|}
\hline \multirow{2}{*}{ Group } & \multicolumn{5}{|l|}{ Average particle count in each animal } \\
\cline { 2 - 6 } & 1 & 2 & 3 & 4 & Mean \pm s.e. \\
\hline I & 3.39 & 2.44 & 2.39 & 1.94 & $2.54 \pm 0.3^{* a}$ \\
II & 1.07 & 1.10 & 0.82 & 0.72 & $0.93 \pm 0.09^{*}$ \\
III & 7.12 & 4.82 & 5.64 & 7.43 & $6.25 \pm 0.62^{\mathrm{a}}$ \\
IV & 1.09 & 0.64 & 0.82 & - & $0.85 \pm 0.13^{*}$ \\
\hline
\end{tabular}

Group I = Animals treated with dexamethasone

Group II = Animals treated with promethazine

Group III = Animals—control (infected, untreated)

Group IV = Animals-uninfected, untreated controls

* Significantly different $(P<0.05)$ from the infected, untreated control

a Significantly different $(P<0.05)$ from the uninfected control

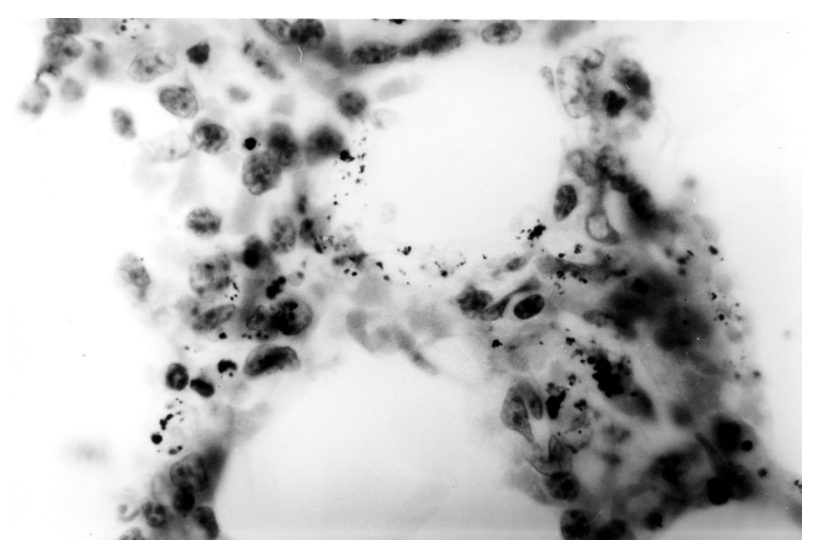

FIG. 2 Photomicrography of the lung of a steer infused with tattoo ink (ECF case-untreated control): Note the distribution and preponderance of tattoo ink particles. $\mathrm{H}$ \& $\mathrm{E}$ X 1000

The vascular permeability study revealed that tattoo ink particles passed through capillary endothelial walls into the interstitium of the lung while some had passed into the alveolar lumens (Table 3; Fig. 2 and 3 ). In group III the average tattoo ink particles count was significantly higher $(P<0.01)$ than in the treated groups I and II. The difference between the animals treated with dexamethasone and those treated with promethazine was also significant at the $P<0.05$ level. The particles count in the promethazine group was not significantly different from the uninfected control group.

\section{Experiment II}

All infected cattle developed theileriosis within the first 10 days of infection (Table 4). Lymph node enlargement was detected on day 7.33 and the schizonts were detected on day 7.56 p.i. The aver-

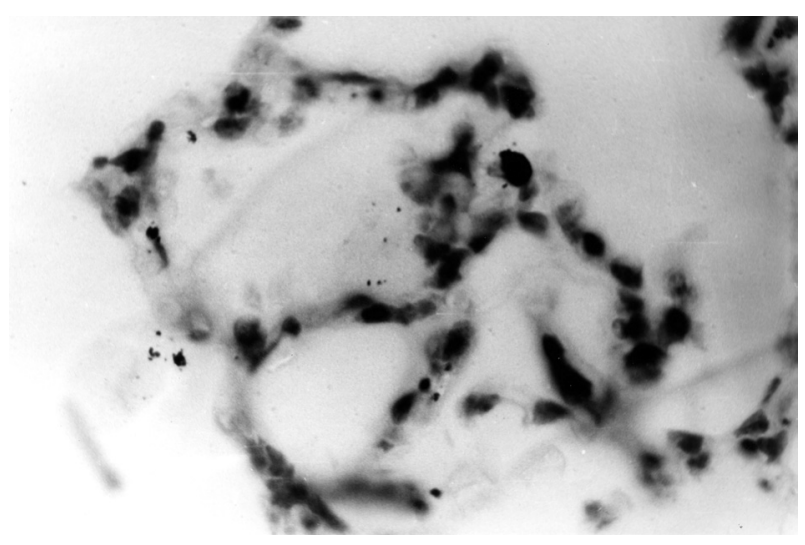

FIG. 3 Photomicrography of lung of a steer infused with tattoo ink (ECF case - treated with dexamethasone): Note the paucity of tattoo ink particles in the alveoli and interstitial tissue. H \& E X 1000

age rectal temperature rose to $39.5^{\circ} \mathrm{C}$ in 8.22 days. At the time of treatment all cattle were suffering from reaction what was judged to be "moderate" theileriosis as per criteria set by Anon. (1989). On day 9.09 their appetites were generally poor. The results of the average schizont score are also summarised in Table 4. At the time of treatment the average score was 3.17 (left prescapular lymph node) and 2.00 (right prescapular lymph node). There was no positive correlation between the schizont score and the severity of the clinical disease. After completion of treatment all animals except one recovered from the clinical disease, the exception being an animal that coughed persistently until day 7 after treatment.

\section{Experiment III}

Clinical and parasitological results for this experiment are shown in Table 5. Only a proportion of 


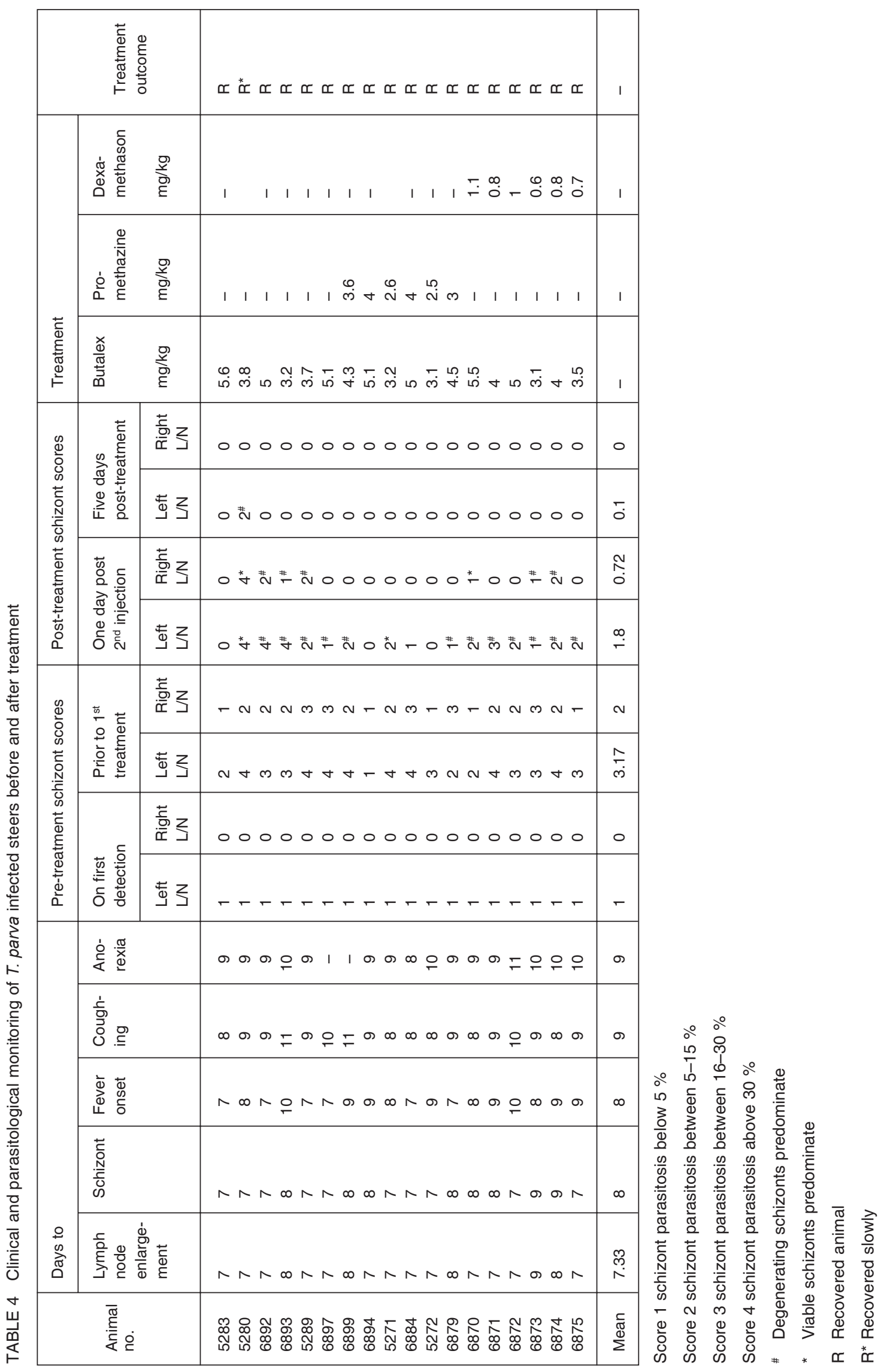


Dexamethasone and promethazine in combination with buparvaquone in East Coast fever

TABLE 5 Clinical and parasitological monitoring of $T$. parva re-infected steers in experiment III

\begin{tabular}{|c|c|c|c|c|c|c|c|c|c|c|c|}
\hline \multirow{3}{*}{$\begin{array}{l}\text { Animal } \\
\text { no. }\end{array}$} & \multicolumn{5}{|l|}{ Days to } & \multicolumn{6}{|c|}{ Schizont scores } \\
\hline & \multirow{2}{*}{$\begin{array}{l}\text { Lymph } \\
\text { node } \\
\text { enlarge- } \\
\text { ment }\end{array}$} & \multirow[t]{2}{*}{ Schizont } & \multirow[t]{2}{*}{$\begin{array}{l}\text { Fever } \\
\text { onset }\end{array}$} & \multirow[t]{2}{*}{ Coughing } & \multirow[t]{2}{*}{ Anorexia } & \multicolumn{2}{|c|}{$\begin{array}{l}\text { On first } \\
\text { detection }\end{array}$} & \multicolumn{2}{|c|}{$\begin{array}{l}7 \text { days after } \\
\text { first detection }\end{array}$} & \multicolumn{2}{|c|}{$\begin{array}{l}14 \text { days after } \\
\text { first detection }\end{array}$} \\
\hline & & & & & & $\begin{array}{l}\text { Left } \\
\text { L/N }\end{array}$ & $\begin{array}{l}\text { Right } \\
\text { L/N }\end{array}$ & $\begin{array}{l}\text { Left } \\
\text { L/N }\end{array}$ & $\begin{array}{l}\text { Right } \\
\text { L/N }\end{array}$ & $\begin{array}{l}\text { Left } \\
\text { L/N }\end{array}$ & $\begin{array}{l}\text { Right } \\
\text { L/N }\end{array}$ \\
\hline 5283 & 13 & 13 & 14 & - & - & 1 & 0 & 0 & 0 & 0 & 0 \\
\hline $5280^{*}$ & 13 & 14 & - & & & 1 & 0 & - & - & - & - \\
\hline 6892 & - & 12 & - & - & - & 1 & 0 & 0 & 0 & 0 & 0 \\
\hline 6893 & 12 & - & - & - & - & 0 & 0 & 0 & 0 & 0 & 0 \\
\hline 5289 & 14 & 14 & - & - & - & 1 & 0 & 0 & 0 & 0 & 0 \\
\hline 6897 & - & - & - & - & - & 0 & 0 & 0 & 0 & 0 & 0 \\
\hline 6899 & - & - & - & - & - & 0 & 0 & 0 & 0 & 0 & 0 \\
\hline 6894 & 13 & 14 & 13 & - & - & 1 & 0 & 0 & 0 & 0 & 0 \\
\hline 5271 & 13 & 12 & - & - & - & 1 & 0 & 0 & 0 & 0 & 0 \\
\hline 6884 & - & 13 & - & - & - & 1 & 0 & 0 & 0 & 0 & 0 \\
\hline 5272 & 12 & 12 & - & - & - & 1 & 0 & 0 & 0 & 0 & 0 \\
\hline 6879 & 14 & 14 & - & - & - & 1 & 0 & 0 & 0 & 0 & 0 \\
\hline 6870 & 13 & 13 & - & - & - & 1 & 0 & 0 & 0 & 0 & 0 \\
\hline 6871 & 13 & 14 & - & - & - & 1 & 0 & 0 & 0 & 0 & 0 \\
\hline 6872 & 11 & 13 & - & - & - & 1 & 0 & 0 & 0 & 0 & 0 \\
\hline 6873 & 13 & 14 & 13 & - & - & 1 & 0 & 0 & 0 & 0 & 0 \\
\hline 6874 & - & 13 & - & - & - & 1 & 0 & 0 & 0 & 0 & 0 \\
\hline 6875 & - & 14 & - & - & - & 1 & 0 & 0 & 0 & 0 & 0 \\
\hline Mean & 12.8 & 13.3 & 13 & - & - & 0.83 & 0 & 0 & 0 & 0 & 0 \\
\hline
\end{tabular}

Score 1 schizont parasitosis below $5 \%$

Score 2 schizont parasitosis between $5-15 \%$

Score 3 schizont parasitosis between 16-30\%

Score 4 schizont parasitosis above $30 \%$

* Died on day 16 post infection

challenged animals showed clinical and parasitological changes at variable time points. Lymph node enlargement was detected on day 12.83 p.i. in $66.67 \%$ of infected animals and the T. parva schizonts were detected on day 13.26 p.i. in $83.33 \%$ of infected animals, whereas fever was detected on day 13.33 p.i. in $16.67 \%$ of infected animals. However, these changes were mild and disappeared without medical intervention. The sizes of lymph nodes decreased to the normal sizes in 4 days and schizonts could not be detected in the lymph nodes during subsequent screening (on days 7 and 14 after first detection). The temperature reaction persisted for 2 days only.

The other two susceptible animals developed severe ECF within 10 days of infection that necessitated specific medical intervention. These animals recovered promptly following treatment with buparvaquone.

\section{DISCUSSION}

This study has provided useful results on the role of dexamethasone and promethazine in the modulation of the clinical outcome of ECF. The two drugs were equally effective in mitigating the dyspnoea, which is a typical clinical sign of this disease. The clinical finding was matched by the necropsy findings, as treated animals had scanty fluid /froth in the pulmonary airways. Insignificant increases in lung mass in the treated animal groups also supported that there was minimal fluid formation and accumulation in the interstitial tissues and alveolar spaces (Staub, Nagano \& Pearce 1967). The successful mitigation of dyspnoea attributable to pulmonary oedema indicates that the use of these drugs would be beneficial in those cases of ECF manifesting respiratory distress. Surprisingly, when these drugs were used together with the theilericidal drug, no significant difference in response 
between the groups receiving the combination chemotherapy and that receiving buparvaquone alone was noted (Experiment II). The insignificant differences observed in the response to the various chemotherapy combinations might be attributed to intervention with specific antitheilerial treatment fairly early in the course of disease at a stage before pulmonary oedema develop into a critical state. Treatments with glucocorticoids and antihistamines are likely to have a more significant effect in protracted cases in which pulmonary oedema is in an advanced stage and usually the immediate cause of death.

The use of tattoo ink (carbon particles) demonstrated that there was a reduction in vascular permeability in the animals treated with dexamethasone and promethazine. The abundance of the carbon particles in the alveoli in the infected untreated control animals suggests an increased escape of the particles from blood vessels through the vascular endothelium as a result of increased vascular permeability. Compared with dexamethasone at the dosage given, promethazine was more effective than dexamethasone in ameliorating pulmonary oedema if the tattoo ink particle count is taken into account. Nevertheless, promethazine was only partially protective against the morphologic changes that occurred in the lungs. In view of these findings, it is considered that oedema formation in ECF is probably largely attributable to histamine release in the lungs during the disease process. This contention is strongly supported by the narrow pharmacological spectrum of promethazine as being only a competitive antagonist to $\mathrm{H}_{1}$-receptors in tissue cells. As a result promethazine would probably not contribute significantly to the preservation of the morphology of the lungs as was observed in the dexamethasone treated cattle. This may be explained by the fact that several mediators act jointly to produce hypersensitivity reactions in cattle (Black \& Burka 1979; Semrad 1993). The preservation of lung morphology by dexamethasone may also be of clinical significance as far as the effectual performance of the lungs is concerned. The wide range of therapeutic effects induced by glucocorticoids may contribute to this (Black \& Burka 1979; Haskins 1992; Morris 1992; Semrad 1993; Fubin, Boatwright, Todhunter \& Lust 1993; Adams 2001).

The finding that the animals in Experiment II that recovered following the treatment were refractory to a subsequent challenges with $T$. parva indicates that steers treated early in the course of ECF are subsequently immune. This phenomenon mimics the infection and treatment method (ITM) of immunizing cattle against ECF.
We therefore conclude that dexamethasone and promethazine prevent oedema formation in experimental $T$. parva infections and may have a significant palliative role in the management of advanced clinical cases of ECF, of which pulmonary oedema is a critical factor.

\section{ACKNOWLEDGEMENTS}

The authors acknowledge the financial support of the Norwegian Agency for Development Cooperation (NORAD).

\section{REFERENCES}

ADAMS, H.R. (Ed.) 2001. Veterinary pharmacology and therapeutics, $8^{\text {th }}$ ed. Ames: lowa State University Press.

ANON. 1989. Classification of Theileria parva reactions in cattle, in Theileriosis in Eastern, Central, and Southern Africa. Proceedings of a Workshop on East Coast Fever Immunization Held in Lilongwe, Malawi, 20-22 September 1988, edited by T.T. Dolan. Nairobi: International Laboratory for Research on Animal Diseases: 187-188.

BANCROFT, J.D. \& STEVENS, A. 1990. Theory and practice of histological techniques, $2^{\text {nd }}$ ed. London: Churchill Livingstone.

BLACK, L. \& BURKA, J.F. 1979. Hypersensitivity in cattle. Part III. The mediators of anaphylaxis. Veterinary Bulletin, 49:303308.

BURRIDGE, M.J. \& KUMBER, C.D. 1972. The indirect fluorescent antibody test for experimental East Coast fever. Research in Veterinary Science, 13:451-455.

FUBIN, S.L., BOATWRIGHT, C.E., TODHUNTER, R.J. \& LUST, G. 1993. Effect of intramuscular administered polysulfated glycosaminoglycan on articular cartilage from equine joints injected with methylprednisolone acetate. American Journal of Veterinary Research, 54:1359-1365.

HASKINS, S.C. 1992. Management of septic shock. Journal of the American Veterinary Medical Association, 200:19151924.

JUBB, K.V.F., KENNEDY, P.C. \& PALMER, N. 1992. Pathology of domestic animals. Vol. 3, $5^{\text {th }}$ ed. San Diego: Academic Press.

LAWRENCE, J.A., DE VOS A.J. \& IRVIN, A.D. 1994. East Coast fever, in Infectious disease of livestock with special reference to southern Africa. Vol. 1, edited by J.A.W. Coetzer, G.R. Thomson \& R.C. Tustin. Cape Town: Oxford University Press.

MATOVELO, J.A., MWAMENGELE, G.L.M. \& MBASSA, G.K. 2000. The suppressive effects of dexamethasone on the development of pulmonary oedema in East Coast fever. Tropical Animal Health and Production, 32:353-356.

MBWAMBO, H.A., MKONYI, P.A. \& CHUWA, R.B. 1984. Field trial to determine efficiency of parvaquone against naturally occurring cases of East Coast fever, Proceedings of the $2^{\text {nd }}$ Tanzania Veterinary Association Scientific Conference, Arusha, Tanzania, 2:45-59.

MBWAMBO, H.A., MKONYI, P.A. \& CHUWA, R.B. 1987. Field evaluation of parvaquone against naturally occurring East Coast fever. Veterinary Parasitology, 23:161-168. 
MBWAMBO, H.A., SUDI, F.F., MKONYI, P.A., MFINANGA, J.M., MELLA, E.S. \& NGOVI, C.J. 2002. Comparative studies of the efficacy of parvaquone and parvaquone-plusfrusemide in the treatment of Theileria parva infection (East Coast fever) in cattle. Veterinary Parasitology, 103:195-205.

MCHARDY, N., WEKESA, L.S., HUDSON, A.T. \& RANDALL, A.W. 1985. Antitheilerial activity of BW720C (buparvaquone): A comparison with parvaquone. Research in Veterinary Science, 39:29-33.

MORRIS, D.D. 1992. Disseminated intravascular coagulation, in Equine current therapy. Vol. III, edited by N.E. Robinson. Philadelphia: W.B. Saunders Co.

MUKHEBI, A.W., PERRY, B.D. \& KRUSKA, R. 1992. Estimated economics of theileriosis control in Africa. Preventive Veterinary Medicine, 12:73-85.

NORVAL, R.A.I., PERRY, B.D. \& YOUNG, A.S. 1992. The Epidemiology of Theileriosis in Africa. London: Academic Press.

SEMRAD, S.D. 1993. Effect of phenylbutazone and repeated endotoxin administration on hemostasis in neonatal calves. American Journal of Veterinary Research, 54:1339-1346.
SHITAKHA, V.M., MUSOKE, A.J., RAMASAMY, R. \& BUSCHER, G. 1983. Compliment activation and fibrinolysis during infection with Theileria parva (East coast fever) in cattle. Veterinary Immunology and Immunopathology, 4:361-373.

SLAUSON, D.O. \& COOPER, B.J. 2001. Mechanisms of diseases: A textbook of comparative general pathology, $3^{\text {rd }}$ ed. St. Louis: Mosby.

STAUB, N.C., NAGANO, H. \& PEARCE, M.L. 1967. Pulmonary edema in dogs, especially the sequence of fluid accumulation in lungs. Journal of Applied Physiology, 22:227-234.

THAIYAH, A.G., CHEGE, J.N., MURIUKI, S.K. \& WEKESA, L.S. 1993. Efficacy of buparvaquone in the treatment of East Coast fever cases in the Kabete area of Kiambu District of Kenya: Preliminary result. Bulletin of Animal Production in Africa, 41:333-335.

YOUNG, P.L. \& SPRADBROW, P.B. 1990. Demonstration of vascular permeability changes in cattle infected with bovine ephemeral fever Virus. Journal of Comparative Pathology, 102:55-62. 